\title{
Nalar Politik, Kekuasaan, Dan Etika Jawa Refleksi Konsep Hasta Brata Tatanan Kehidupan Masyarakat Jawa Kontemporer
}

\author{
Mibtadin \\ Universitas Sebelas Maret \\ mibtadianisahmad@staff.uns.ac.id
}

\section{Article History}

received $1 / 9 / 2021$

\begin{abstract}
Javanese culture is a noble value order as a form of embodiment of all human actions in overcoming various problems related to life and life, both social, economic, cultural institutions, and even leadership styles. In Javanese political ethics, it is known as the concept of hasta brata which is the essence of the noble values of culture as a form of depicting the ideal leader. The hasta brata teaching is one of the teachings in wayang kulit, its contents are about the eight elements of the nature of bearinga, samirana, candra, solar, ocean, kartika, sky, and dahana, each of which has its own philosophical meaning, namely the teachings of character or ethics. Hasta brata is a political way that prioritizes ethics and social systems created by leaders to provide coolness and peace, eradicate crime, be wise, patient, friendly and gentle, see, understand and live up to all the needs of their people, provide welfare and assistance to people in need. , able to accommodate everything that comes to him, whether pleasant or not, and can provide a lamp for the people.
\end{abstract}

Keywords: Political Reason, Javanese Ethics, Hasta Brata, Leadership

\begin{abstract}
Abstrak
Budaya Jawa merupakan tatanan nilai yang adiluhur sebagai bentuk perwujudan semua tindakan manusia dalam mengatasi berbagai persoalan yang berkaitan dengan hidup dan kehidupan, baik pranata sosial, ekonomi, budaya, bahkan gaya kepemimpinan. Dalam etika politik masyarakat Jawa dikenal sebagai konsep hasta brata yang merupakan sari pati dari nilai luhur budaya sebagai bentuk penggambaran pemimpin ideal. Ajaran hasta brata merupakan salah satu ajaran yang dalam wayang kulit, isinya tentang anasir delapan perwatakan sifat alam bantala, samirana, candra, surya, samudra, kartika, angkasa, dan dahana, masing -masing mempunyai makna filosofi tersendiri yaitu ajaran budi pekerti atau etika. Hasta brata adalah cara berpolitik yang mengedepankan etika, dan sistem sosial yang diciptakan pemimpin untuk memberi kesejukan dan ketentraman, membasmi kejahatan, bersifat bijaksana, sabar, ramah dan lembut, melihat, mengerti dan menghayati seluruh kebutuhan rakytanya, memberikan kesejahteraan dan bantuan bagi masyarakatnya yang memerlukan, mampu menampung segala sesuatu yang datang kepadanya baik yang menyenangkan maupun yang tidak, dan dapat memberikan pelita bagi masyarakatnya.
\end{abstract}

Kata kunci: Nalar Politik, Etika Jawa, Hasta Brata, Kepemimpinan

Social, Humanities, and Education Studies (SHEs): Conference Series $\quad$ p-ISSN 2620-9284 https://jurnal.uns.ac.id/shes

e-ISSN 2620-9292 


\section{PENDAHULUAN}

Budaya Jawa merupakan tatanan nilai yang adiluhur sebagai bentuk perwujudan semua tindakan manusia dalam mengatasi berbagai persoalan yang berkaitan dengan hidup dan kehidupan (Damami, 2002: 8). Sedangkan unsur universal sebuah kebudayaan meliputi tujuh sistem: (1) sistem religi, (2) sistem organisasi masyarakat, (3) sistem bahasa, (4) sistem pengetahuan, (5) sistem kesenian, (6) sistem mata pencaharian, serta (7) sitem teknologi dan peralatan. Semua sistem kebudayaan tersebut terdapat dalam masyarakat dari tingkatan primitif hingga masyarakat dalam tingkatan modern, dan sistem budaya tersebut mengalami dinamika sebagai akibat pergaulan antar masyarakat pendukungnya dengan kebudayaan lain (Prabowo, 2003: 4). Dengan memperhatikan tujuh sistem budaya tersebut, secara umum wong Jawa memiliki karakteristik budaya yang khas sesuai dengan kondisi sosial kemasyarakatannya.

Secara umum, budaya Jawa dapat dibagi menjadi dua: pertama, budaya lahir, dan kedua, budaya batin (Prabowo, 2003: 25). Pertama, budaya lahir merupakan segala hal yang terkait dengan kedudukan masyarakat Jawa sebagai makhluk individu maupun makhluk sosial. Dalam hal ini budaya Jawa memiliki kaidah-kaidah yang dapat dengan mudah diindetifikasi berdasarkan ungkapan-ungkapan budaya sebagai manifestasi nilai-nilai budaya yang didukung oleh masyarakatnya. Kedua, budaya batin berhubungan dengan segala sesuatu yang terkait dengan persoalan-persoalan yang bersifat supranatural dan kekuatan-kekuatan adikodrati yang tidak dapat di empiriskan dan objektifkan (Mibtadin, 2016: 31).

Dalam perjalanannya, sejarah Jawa yang yang mulai berkembang sejak Kerajaan Mataram I hingga sekarang ini, banyak konsep budaya Jawa yang merupakan bentuk sinkretisme budaya pra Hindu-Budha, Hindu-Budha, dan Islam masih dipertahankan di berbagai aspek seperti pendidikan formal, berbagai macam ideologi, bahkan perpolitikan modern. Nilai budaya Jawa masih erat dalam aspek tersebut. Dalam hal politik, pemikiran atau konsep budaya Jawa sangat berpengaruh di dalam sebuah kekuasaan. Kekuasaan merupakan keseluruhan kemampuan, hubungan, atau proses yang melahirkan ketaatan dari pihak lain untuk mencapai tujuan yang usdah ditetapkan oleh pemegang kekuasaan. Kemampuan tersebut sangat dipenagruhi oleh faktor budaya, dalam hal ini budaya Jawa, sekaligus menjadi variabel penting dalam sebuah pemahaman perkembangan politik suatu bangsa atau masyarakat yang dipengaruhi nilai yang ada dalam masyarakat itu sendiri. Dalam budaya Jawa, sebuah kekuasaan tidak hanya berorientasi pada cara mempengaruhi pihak lain, tetapi pada kesetiaan untuk menjalankan kewajiban, rasa ikhlas, dan pengabdian yang tumbuh karena adanya pengaruh sosial kultural budaya Jawa yang bersifat adikodrati. Begitu pula kriteria, kemampuan, dan karakter pemimpin dipengaruhi kondisi alam semesta sebagai "jagat gede" yang bercorak spiritual.

Konsep pemikiran kekuasaan, nalar politik, dan gaya pemimpin yang berkembang dalam masyarakat Jawa secara umum didasarkan pada interaksi antara kepentingan dengan nilai lokal sehingga memunculkan terbentuknya sistem politik budaya Jawa. Konsep kepemimpinan nasional dewasa ini merupakan bentuk representasi pemikiran budaya Jawa yang adiluhng yaitu hasta brata. Konsep ini disarikan dari nilai-nlai luhur budaya Jawa terutama yang ada dalam pewayangan Mahabarata terutama lakon Wahyu Mahkutarama sebagai bentukpenggambaran peimpin yang ideal. Makalah ini ingin memotret antara nalar politik, kekuasaan, dan etika Jawa yang dikaitkan dengan konsep hasta brata serta relevansinya untuk kehidupan masyarakat Jawa modern dewasa ini. 


\section{HASIL DAN PEMBAHASAN}

\section{Pengertian Hasta Brata: Nuladha Lakuning Jagat}

Hasta berarti delapan sedang brata berarti laku, watak, atau sifat utama yang diambil dari sifat alam. Hasta brata adalah delapan laku, watak, atau sifat utama yang harus dipegang teguh dan dilaksanakan pemimpin (Suseno, 2007: 7). Pengertian lain, hasta brata sebagai ilmu laku delapan perwatakan alam, bumi, air, angin, samudra, rembulan, matahari, api, dan bintang yang dimiliki raja besar adil, berwibawa, arif dan bijaksana yang dulu direpresentasikan Pabu Ramawijaya, Prabu Kresna, dan Prabu Parikesit. Ajaran hasta brata awalnya adalah pitutur dan wejangan yang diberikan Rama pada Prabu Gunawan Kudya Wibisana. Ajaran tersebut ada dalam Serat Rama Jarwa Macapat, tertuang pada pupuh 27 Pangkur, jumlah bait 35 buah (Marwanto, 2000: 49)

Hasta brata adalah simbol alam semesta, yatu delapan laku yang mengambil simbol alam, tetapi sejatinya menyiratkan keharmonisan sistem alam semesta. Kedelapan sifat tersebut adalah manifestasi keselarasan yang ada pada tata alam semesta ciptaan Tuhan, dan manusia harus menyelaraskan diri dengan tata alam semesta kalau ingin selamat dan terhindar malapetaka. Manusia sebagai ciptaan Tuhan, bisa selaras dengan alam semesta, maka selaraslah kehidupannya. Dalam konsep Islam dikenal sebagai habl min Allah, habl min nass, dan habl min alam. Karena itu, delapan simbol alam itu adalah bantala (bumi, Dewa Antaboga), Dahana (geni, Dewa Brama), tirta (banyu, Dewa Baruna), maruta (angin, Dewa Bayu), Surya (srengenge, Dewa Surya), candra (bulan, Dewa Candra), kartika (lintang, Dewa Kuwera), dan mega (awan, Dewa Endra). Mengambil kedelapan simbol alam sebagai inti ajaran (core values) hasta brata, sebagai pedoman tingkah laku seorang pemimpin.

Secara umum, hasta brata dapat diapahami sebagai cara berpolitik, etika, dan sistem sosial yang diciptakan pemimpin untuk memberikan kesejukan dan ketentraman pada masyarakatnya, membasmi kejahatan dengan tegas tanpa pandang bulu, bersifat bijaksana, sabar, ramah dan lembut, melihat, mengerti dan menghayati seluruh warganya, memberikan kesejahteraan dan bantuan bagi masyarakatnya yang memerlukan, mampu menampung segala sesuatu yang datang kepadanya baik yang menyenangkan maupun yang tidak, gigih dalam mengalahkan musuh dan dapat memberikan pelita bagi masyarakatnya. Seperti yang disebutkan di atas, konsep hasta brata meneladani laku atau perwatakan 8 (delapan) anasir alam semesta dalam kehidupannya sehari-hari. Pertama, hambeging surya (wataknya matahari) yang maknanya daya, energi, kekuatan atau power pada masyarakatnya. Selain itu perjalanan matahari sejak terbit di timur hingga terbenam di barat menunjukan suatu perjalanan yang istiqomah (alon maton, alon-alon asalkelakon)'

Kedua, hambeging candra (wataknya bulan), selalu memberi penerang atau pepadhang kepada siapa pun saja dan menggambarkan nuansa keindahan religius spiritual yang mengarah selalu bermusyahadah atau mengingat Allah kepada kebesaran dan keindahan-Nya. Ketiga, hambeging kartika (wataknya bintang), menggambarkan kepribadian, maqom atau posisi, bahkan cita-cita yang tinggi, kukuh dan bersifat tetap seperti bintang yang berada di langit. Keempat, hambeging samudra (wataknya lautan), luas hati dan siap menerima keluhan atau menampung beban orang banyak tanpa perasaan keluh kesah. Kelima, hambeging samirana (wataknya angin), selalu meneliti dan menelusup kemana-mana sehingga benar mengetahui secara persis persoalan yang ada di masyarakat. Keenam, hambeging dahana (watanya api) yang selalu menyelesaikan masalah dengan adil serta tidak membedakan antara yang satu dengan yang lainnya (tan pilih kasih, mbang cindil mbang ciladan). Ketujuh, hambeging tirta (wataknya air), selalu mengalir ke tempat yang lebih rendah dan bersikap andap asor anarogo atau rendah hati dalam kehidupan 
sehari-hari. Kedelapan, hambeging kisma (wataknya bumi), maknanya kaya, suka berderma, kaya hati (lembah manah, legowo).

Sedangkan dalam versi yang lain, menurut Yasadipura I, konsep hasta brata merupakan delapan prinsip kepemimpinan berdasarkan sifat alam yang secara filosofis ditiru. Pertama, mahambeg mring kisma (nuladha lakuning bumi), bumi sifatnya tenang, anteb, dan dadi sarana panguripan, pemimpin harus menjadi sumber kebutuhan hidup bagi siapapun, dia mengerti apa yang dibutuhkan masyarakatnya, dan memberikan kehidupan kepada siapa saja tanpa pilih kasih. Serta selalu memberikan pelayanan kepada siapa saja tanpa harus pilih kasih dan tidak menunjukkan sifat sombong. Kedua, mahambeg mrih warih (nuladha lakuning banyu), mengair dari tempat yag tinggi ke yang lebih rendah, sejuk, dan menjadi sarana panguripan sagungung dumadi. Pemimpin harus bisa menyatu dengan masyarakatnya sehingga bisa mengetahui apa yang dibutuhkan mereka, selain itu mereka juga mereasa nyaman, sejuk, dan damai karena bersama pemimpinnya. Pemimpin adalah mitra kerja bagi masyarakat dalam membangun negara ini, tanpa rakyat pemimpin tidak ada yang dipimpin, karena itu jika ingin kekuasaannya langgeng maka ia harus dekat dan selalu "mengalir" bersama rakyat.

Ketiga, mahambeg mring samirana (nuladha lakuning hawa), berwataka hadir dan menyapa disetiap tempat tanpa terkecuali dan adauntuk siapa saja. Pemimpin harus bisa berada di semua tempat, strata sosial, dan komunitas bersikap adil tanpa pandang bulu, tanpa diskriminatif, dan selalu ada untuk mereka yang membutuhkan. Keempat, mahambeg mring candra (nuladha lakuning mbulan), tenang, sejuk, dan memberikan kebahagaian kepada alam semesta. Pemimpin harus mampu menawan hati rakyatnya dengan sifat keseharian yang jelas, tegas, dan tidak adigang, adigung, adiguna, kumalungkung, ora sapa sira sapa ingsung, sehingga tidak menimbulkan konflik di tengah masyarakat. Pemimpin yang baik adalah mereka yang menyejukan rakyatnya karena auranya memancarkan kebahagiaan, harapan, dan kehidupan baru.

Keenam, mahambeg mring surya (nuladha lakuning srengenge), memberikan sinar kehidupan, kehangatan, dan pepadhang kepada alam semesta, pun juga pemimpin juga harus mampu memberikan energi positif, memberikan petunjuk, dan solusi atas semua masalah yang dihadapi raknyatnya. Ketujuh, mahambeg mring samudra (nuladha lakuning segara), lautan luas tanpa tepi, setiap waktu menampung semua hal baik sampah ataupun benda lainnya, dan mengendapkan semua didasarnya. Pemimpin seperti lautan yang bisa wening pikirane, meneb rasane, dan jembar rasaning, menampung semua aspirasi, kritik saran, masukan, hinaan, cemoohan, dan pujian dengan hati yang lapang, sabar, kasih sayang, dan pengertian terhadap rakyatnya.

Ketujuh, mahambeg mring wukir (nuladha lakuning giri), sifatnya yang tegar, teguh, dan kokoh serta menjulang tinggi harus menjadi inspirasi seorang pemimpin dengan keteguhan hatinya, kekuatan fisiknya, serta kokoh secara psikis sehingga tidak mudah menyerah untuk membela kebenaran untuk rakyatnya. Gunung juga sebagaimana pemimpin juga harus memberikan sanksi, karena ini berdampak baik bagi masyarakat banyak seperti letusan gunung yang akhirnya bisa menyuburkan tanah. Kedelapan, mahambeg mring dahana (nuladha lakuning geni), yang membawa energi positif, kehadirannya membawa kehidupan baru, hambrasta mring angkara. Pemimpin harus mmampu memberikan energi poistif, menghangatkan hati, membakar semangat rakyatnya, mengarahkan kepada kebaikan, memerangi kejahatan, dan memberikan perlindungan kepada rakyatnya agar tercipta kehidupan yang baru. 
Etika Jawa, Kekuasaan, dan Relevansi Hasta Brata dalam nalar Berpolitik Masyarakat Dewasa ini

Etika Jawa merupakan ajaran hidup yang umum dipakai dan berlaku di masyarakat Jawa. IImu dalam etika Jawa adalah ilmu yang mempelajari mengenai adat istiadat, pandangan hidup serta nilai-nilai filsafat yang sedang berlangsung dalam kehidupan bermasyarakat. Menurut Magnis Suseno, etika Jawa merupakan pandangan hidup yang berdasarkan moral, hati nurai serta rasa pada penekanan dimensi dengan keselarasan antara manusia dengan semesta atau lingkungan. Masyarakat Jawa tidak mengenal baik dan jahat melainkan bertindak karena ketidaktahuan, jika ada yang bertindak merugikan orang lain itu dianggap orang yang belum mengerti mana yang baik dan mana yang tidak baik.

Konsep etika Jawa sangat luas, termasuk dalam hal politik, sistem sosial, dan kekuasaan yang menekankan keharmonisan, keselarasan dalam setiap dimensi kehidupan salah satunya dimensi dengan alam. Orang Jawa yang ideal adalah orang Jawa yang mendahulukan kewajibannya terlebih dahulu daripada menuntut hak, termasuk mereka yang menjadi pemimpin. Kerukunan dalam masyarakat Jawa adalah mendahulukan keharmonisan sosial daripada pribadi, artinya semakin besar lingkup komunitasnya semakin mengecil kepentingan kelompok yang ada di dalamnya. Prinsip kerukunan dalam masyarakat Jawa di mana keadaan rukun adalah dimana semua pihak berada dalam kedamaian, suka bekerjasama, saling asah, asih dan asuh. Hal inilah yang menjadi harapan masyarakat jawa baik dalam hubungan keluarga, kehidupan sosial, rukun tetangga dan rukun dalam masyarakat. Kerukunan dilandasi dengan adanya saling percaya antar pribadi. Adanya keterbukaan pada siapa saja, adanya bertanggung jawab dan merasa adanya saling ketergantungan atau rasa kebersamaan. Prinsip kerukunan hidup adalah mencegah terjadinya konflik karena bila terjadi konflik bagi masyarakat jawa akan berkesan secara mendalam dan selalu diingat atau sukar untuk melupakan (Wijasa, 1997: 45).

Kekuasaan dalam etika Jawa merupakan hal yang penting karena menjadi media untuk membangun masyarakat ideal dan negara yang makmur baldatun thayibatun warabun ghafur. Secara umum, kekuasaan merupakan hasil dari interaksi sosial. dalam ilmu sosial, terciptanya aspek kekuasaan itu lahir dari ketidaksamaan antar-kelas social dalam strukturisasi masyarakat. Menurut Andi Beteille, ketidaksamaan tersebut bersumber dari status dan organisasi, dimana status membedakan ada yang tinggi dan rendah, sedangkan organisasi berdasarkan pada sebuah tugas dan wewenang.

Menurut Laswell dan Kaplan, kekuasaan merupakan kemampuan dari pihak penguasa untuk mempengaruhi pihak lain demi tercapainya sebuah ketetapan yang telah dibuat penguasa (AMS, 1992: 82). Menurut. Maclver, kekuasaan dalam masyarakat selalu berbentuk seperti piramida (Aris, 1999: 67). Hal ini didasarkan karena kekuasaan membuktikan dirinya lebih unggul daripada yang lain karena golongan yang berkuasa relatif lebih kecil daripada golongan yang dikuasai. Carter mengemukakan ada dua ciri dalam sebuah kekuasaan, yaitu kepatuhan sukarela dan terpaksa. Dalam kebudayaan Jawa, kekuasaan merupakan hasil dari kemampuan penguasa memusatkan kosmis dalam dirinya sendiri dan kekuasaannya bersifat matempiris (AMS, 1992: 83). Kekuasaan dalam budaya Jawa tidak didasarkan pada langkah secara empiris melainkan bersifat spiritual yang tidak hanya karena gejala khas sosial saja, juga berpedoman pada aspek kultural spiritual yang berarti bagi masyarakat.

Kepemimpinan budaya Jawa tidak terlepas dari banyaknya mitos yang ada. Salah satunya adalah pada pimpinan keraton Mataram yang telah dibagi menjadi dua, Yogyakarta dan Surakarta yang meyakini adanya hubungan dengan kekuatan gaib dari Kanjeng Ratu Kidul (Indraswara, 2013: 30). Hal ini sering diperingati dengan adanya 
beberapa ritual. Terkadang mitos dijadikan sebagai tumpuan gaib pemimpin Jawa agar legitimasinya lebih bisa dipercaya. Setiap jenis kepemimpinan dan etnis memiliki ciri tersendiri, dan mengalami perubahan dari waktu ke waktu mengikuti perkembangan zaman. Dasar pemikiran masyarakat Jawa lebih terpusat pada hal yang bersifat tradisional, sehingga pada kepemimpinannya dalam hal politik pun berbeda dari kepemimpinan etnis lainnya

Salah satunya dalam hal sukesi, kepemimpinan Jawa memiliki kekhasan tersendiri dengan ciri-ciri: pertama, pengganti pimpinan harus trahing kusuma rembesing madu, keturunan sangat dipertimbangkan, dimana trah menjadi syarat utama dalam dunia pimpinan Jawa. Kedua, dipilih pemimpin sebelumnya dengan cara ditunjuk berdasarkan beberapa kriteria, yang ditunjuk tersebut harus sendika dhawuh, yaitu harus mengikuti perintah sehingga tidak boleh menolak. Ketiga, tanpa ada periodisasi kepemimpinan selama yang bersangkutan masih dalam keadaan sehat. Dasar pemikiran hadirnya kekuasaan Jawa, tidak terlepas dari aspek kepemimpinan. Kekuasaan merupakan sebuah identitas diri yang terkadang terpoles dengan agama, ras, dan sejumlah hal (Utomo, 2003: 41). Kekuasaan dibingkai tindakan politik, yang berusaha menguasai orang lain. Kunci politik dan kekuasaan adalah hegemoni pada orang lain. Di dalam kekuasaan dan kepemimpinan ada upaya menaklukkan orang lain. Kekuasaan sosok seorang penguasa dalam pemikiran Jawa juga dipahami sebagai sosok yang memusatkan takaran kekuatan kosmis yang cukup besar dalam dirinya (Sumbullah, 2012: 14). Seorang penguasa yang dianggap berhasil diukur berdasarkan besar kecilnya monopoli kekuasaan yang dipegang olehnya. Selain itu, kekuasaan seorang penguasa juga dapat dilihat dari kesuburan tanah dan ada tidaknya bencana alam. Hal tersebut berdasarkan dari kekuatan kosmis yang berpusat pada diri raja sehingga tidak ada kekuatan lain, termasuk kekuatan alam.

Pada jaman pra-Islam, raja sebagai penguasa dalam sebuah kekuasaan politik dipandang sebagai perwujudan dari sosok dewa. Islam yang sudah membendung seluruh Jawa dengan menolak pandangan tersebut belum berhasil dan masih bertahan di beberapa kalangan hingga saat ini. Hal tersebut dipengaruhi Hindu yang memandang sistematika manusia dalam bentuk hierarkis (Aris, 1999: 23). Penguasa dunia dan kaum priyayi mendapatkan pandangan yang tinggi dan halus, mengarah pada kebenaran dan keadaan yang menguntungkan dibandingkan manusia yang memiliki tingkatan rendah. Pemikiran yang demikian menjadikan ningrat dan priyayi berorientasi ke keraton dengan menekankan sikap hormat sebagai langkah awal perjalanan manusia mendekati Tuhannya, sebagai kawula Gusti. Pandangan masyarakat Jawa memang berakar jauh ke masa lalu, bahkan mereka sudah mengenal Tuhan sebelum datangnya agama-agama yang berkembang sekarang ini. Semua agama yang datang diterima dengan baik oleh masyarakat Jawa tanpa adanya pertentangan antara agama dan keyakinan. Mereka menganggap semua agama itu baik, sedaya agami niku sae (Subqi, 2018: 42). Pada hakikatnya, kenyataan terkait kekuasaan selalu bertentangan dengan kenyataan yang ekuivalen dalam tradisi Jawa hingga diperoleh hubungan timbal balik dan penyesuaian tradisi (Ali, 1986: 51).

Paham kekuasaan Jawa merupakan sebuah paham yang berasal dari pemikiran yang bersifat adikodrati dan transendental, dimana sumber kekuasaan tidak berasal dari hubungan antar-manusia melainkan dari Tuhan, sehingga segala hal yang mendukung kekuasaan juga bersifat adiduniawi dan spiritual (Suyanto, 2005: 72). Hal tersebut berasal dari pernyataan Anderson, budaya kekuasaan Jawa memiliki nilai tradisi (Indrasawara, 2013: 26). Terdapat dua karakteristik turunan dari pernyataan Anderson, yaitu kekuasaan yang cenderung sentralis dan adikodrati. Kekuasaan yang cenderung sentralis didapatkan dalam pengambilan sebuah keputusan elite politik di tingkat paling atas sehingga perlu adanya kontrol yang ketat. Adikodrati adalah kekuasaan berasal dari alam kodrati sehingga tidak memiliki moral secara horizontal 
dan berakibat tidak adanya pertanggungjawaban dalam sebuah keputusan kepada masyarakat secara keseluruhan.

Menurut Anderson, ada empat konsep kekuasaan dari pemikiran budaya Jawa, yaitu konkrit, homogen, jumlah kekuasaan di alam semesta tetap, dan kekuasaan tidak mempersoalkan keabsahan (Wicaya, 2013: 59). Pertama, kekuasaan bersifat konkrit, yaitu sebuah penjelas bahwa kekuasaan itu memang ada dan keberadaannya diturunkan Tuhan Yang Maha Esa melalui wakilnya. Kekuasaan bukanlah suatu anggapan teoritis saja, melainkan memang realita. Dalam pemikiran tradisional Jawa, tidak ada sebuah garis batasan antara zat organik dan non-organik, karena segala sesuatunya dipangku oleh kekuasaan yang kasat mata(Aris, 1999: 62). Kekuasaan dianggap sebagai daya yang mengaitkan paham animisme desa dengan pateisme metafisik perkotaan (Indraswara, 2013: 46). Kedua, kekuasaan bersifat homogen, kekuasaan itu sama jenisnya dan berasal dari sumber yang sama. Konsep hasta brata ini berbeda dengan konsep kekuasaan teori Barat yang memandang kekuasaan ini heterogen yang kekuasaannya berdasarkan pada status sosial, senjata, kepandaian, jumlah penduduk, dan lain-lain (Wicaya, 1991: 51).

Ketiga, dalam hasta brata bahwa jumlah kekuasaan di alam semesta tetap, masyarakat Jawa memandang alam semesta tidak bertambah luas dan sempit, yang berpindah hanyalah konstelasi dan tata letaknya saja. Dalam praktik politik, terdapat konsekuensi dari paham ini yaitu adanya konsentrasi kekuasaan pada suatu tempat. Seiring berkembangnya zaman, konsep pemahaman ini bisa dipengaruhi adanya perkembangan teknologi, sehingga kekuasaan terus bertambah. Keempat, kekuasaan tidak mempersoalkan keabsahan, tidak adanya permasalah yang membahas terkait darimana itu sebuah kekuasaan. Masyarakat Jawa tidak mengenal sah dan tidak sah. Dalam hal ini, masyarakat Jawa tidak memberlakukan ungkapan seperti kekuasaan berdasarkan kekayaan adalah sah, sebaliknya kekuasaan berdasarkan senjata adalah tidak sah. Kekuasaan dalam konsep pemikiran masyarakat Jawa adalah terkait konkrit dan ada.

Masyarakat Jawa menyadari bahwa kedudukan, kekuasan, dan nalar politiknya dalam kehidupan di dunia ditentukan adanya faktor esensial imanen yang disebut sebagai "kewahyon" atau titah pinilih pinesthi bentuk takdir yang telah ditentukan Allah Swt sebelum manusia lahir. Karena itu, dalam masyarakat Jawa dikenal adanya konsep "ratu adil" taitu konsep kekuasaan yang dikaitkan kekuatan kosmis, adi kodrati, dan bersifat transenden (Aris, 1999: 27). Seluruh konsep kekuasaan dalam masyarakat Jawa pada dasarnya bersumber dari krenteg dan kesakten yang digunakan dalam prinsip etika untuk memayu hayuning pribadi, keluaga, bangsa, dan bawana. Makna kesakten tidak hanya sempit sebagai kekuatan yang luar biasa, tetapi dipahami sebagai lain yaitu kemampuan untuk menyelaraskan kekuatan kosmis dan non kosmis untuk menggerakan nalar politik, kekuasaan, dan kepemimpinan dalam bentuk sistem kenegaraan. Sistem kepemimpinan dalam masyarakat Jawa memlii karakter yang universal seperti harus berlaku adil paramarta tan pilih kasih, murah hati luber, dan bijaksana atau wicaksana ebagaimana pengaruh dari konsep kosmis alam semesta yang diserap melalui kesadaran dan "kesaktian" para pemimpin.

Dalam konsep masyarakat Jawa, gaya kepemimpinan tersebut tercermin pada hasta brata dimana pemimpin haris memiliki karakteristik khusus seperti kreatif, inovatif, transformatif, kharisma, dan bijaksana. Karena itu, pemimpin yang ideal dalam masyarakat Jawa kontemporer ini adalah yang bisa menjadi lokomotof perubahan, membawa perdamaian, dan transformasi nasional secara cerdas dan berintegritas. Pemimpin yang melayani, memberdayakan, menyejahterakan warga masyarakatnya, yang selalu hadir "ada dan berada" bersama rakyatnya dengan mengedepankan watak yang jujur, merakyat, dan sederhana. Pemimpin ideal dalam konsep etika dan nalar politik masyarakat Jawa adalah mereka yang mampu mentransformasikan delapan 
laku kosmis dalam parktik kepemimpinan nasional dewasa ini sebagai bentuk implementasi hasta brata yaitu berwatak seperti bantala, samirana, candra, surya, samudra, kartika, angkasa, dan dahana.

\section{SIMPULAN}

Budaya Jawa merupakan tatanan nilai yang adiluhur sebagai bentuk perwujudan semua tindakan manusia dalam mengatasi berbagai persoalan yang berkaitan dengan hidup dan kehidupan, baik pranata sosial, ekonomi, budaya, bahkan gaya kepemimpinan. Dalam etika Jawa dikenal sebagai konsep hasta brata yang merupakan sari pati dari nilai luhur budaya sebagai bentuk penggambaran pemimpin idel. Ajaran hasta brata merupakan salah satu ajaran yang dalam wayang kulit, isinya tentang anasir delapan perwatakan sifat alam bantala, samirana, candra, surya, samudra, kartika, angkasa, dan dahana, masing -masing mempunyai makna filosofi tersendiri yaitu ajaran budi pekerti atau etika termasuk dalam kepemimpinan dan memegang kekuasaan. Sebab etika adalah bagian dari pendidikan Islam, karena pendidikan Islam mengajarkan karimah, dengan demikian ajaran ini masih relevan dijadikan dasar hidup guna menata kehidupan yang lebih baik.

\section{DAFTAR PUSTAKA}

Ali, F. (1986). "Refleksi Paham "Kekuasaan Jawa" dalam Indonesia Modern. Jakarta: PT Gramedia.

AM, S. (1992). "Konsep Kekuasaan dalam Tradisi Budaya Jawa". dalam Jurnal Cakrawala Pendidikan, Vol 1, No 02.

Aris. (1999). Gkonsep Kekuasaan Dalam Budaya Jawa, UIN Sunan Ampel Surabaya, Aqidah Filsafat Islam. Surabaya: Digital Library UIN Sunan Ampel.

Damami, M. (2002). Makna Agama dalam Masyarakat Jawa, Yogyakarta: LESFI.

Imam, Subqi, 2018, Islam dan budaya Jawa, Surakarta: Taujih.

Indraswara, DS, 2013, Falsafah Kepemimpinan Jawa, Yogyakarta: NARASI.

Isbodroini, Suyanto GD, 2005, "Paham Kekuasaan Jawa: Pandangan Elit Kraton Surakarta dan Yogyakarta”, dalam Jurnal Antropologi Indonesia, Vol 01, No 05.

Marwanto, Budhy Moehanto, 2010, Apresiasi Wayang, Surakarta: CV Cendrawasih.

Prabowo, Dhanu Priyo, dkk, 2003, Pengaruh Islam dalam Karya-karya Ronggo Warsito, Yogyakarta: Narasi.

Sumbullah, Umi, 2012, "Islam Jawa dan Akulturasi Budaya: Karakteristik, Variasi, dan Ketaatan Ekspresif", dalam Jurnal el-Harokah, Vol 2, No 1.

Susetya, Wawan, 2002, Kepemimpinan Jawa, Yogyakarta : Narasi.

Tim Sena Wangi, 1999, Ensiklopedi Wayang Indonesia, Jakarta: Sena Wangi.

Utomo, W W, 2013, Budaya Politik dalam Etnis Jawa, Medan: IAIN Sumatera Utara.

Wicaya, J, 1991, Konsep Kekuasaan Jawa dalam Kehidupan Sosial Politik Indonesia, Yogyakarta: Pustaka Media.

Wiyasa, T, 1997, Mengungkap dan Mengenal BudayaJjawa, Jakarta: PT. Pradnya Paramita. 